\title{
AN EVALUATION OF PATIENT SATISFACTION WITH CUSTOM-FIT PROSTHESIS OF EYE IN A TERTIARY EYE CARE CENTRE
}

\author{
Usha Kim¹, K. S. Rajiv Krishna ${ }^{2}$
}

1 Professor and HOD, Department of Orbit, Oculoplasty and Ocular Oncology, Aravind Eye Hospitals, Madurai.

${ }^{2}$ Assistant Professor, Department of Ophthalmology, Government Siddhartha Medical College, Vijayawada.

\section{ABSTRACT}

\section{BACKGROUND}

Custom fit prostheses are commonly placed to improve cosmesis in patients with loss of eyeball due to myriad reasons including trauma, eye diseases and congenital anomalies. Patient satisfaction and comfort with the custom-fit prosthesis is the key factor for successful physical, social and psychological rehabilitation.

The objective of this study is to evaluate subjective satisfaction in patients with custom-fit prosthesis of the eye.

\section{MATERIALS AND METHODS}

200 patients with CFP attending the orbit and oculoplasty OPD at Aravind Eye Hospital and Postgraduate Institute during 2015 were clinically examined and subjective satisfaction was evaluated based on responses to a questionnaire.

\section{RESULTS}

Overall, a majority (95\%) of patients were satisfied. Common causes reported to cause discomfort were pain, irritation, watering and discharge. These problems were mostly overcome by patient and family education and counselling on the CFP fitting and maintenance.

\section{CONCLUSION}

CFPs provide simple and effective solution to cosmetic devastation due to eyeball loss and assist in physical and psychological healing.

\section{KEYWORDS}

Custom-Fit Prostheses of the Eye, Patient Satisfaction, Cosmesis.

HOW TO CITE THIS ARTICLE: Kim U, Krishna KSR. An evaluation of patient satisfaction with custom-fit prosthesis of eye in a tertiary eye care centre. J. Evolution Med. Dent. Sci. 2017;6(61):4503-4506, DOI: 10.14260/Jemds/2017/973

\section{BACKGROUND}

Loss of eye may be consequent to congenital and acquired causes including trauma, malignancy, infectious, inflammatory and degenerative conditions. It causes devastating effects like visual loss and psychological problems due to disfigurement, scarring, improper development of orbital bones and loss of facial symmetry if left unaddressed. Custom-fit prostheses help restore facial symmetry and near-normal appearance of the patient. Early restoration of socket structure and orbital volume is necessary and may be challenging in special patient categories such as children. ${ }^{1}$

Subjective patient satisfaction is the main goal in CFP placement. There are no studies addressing this topic according to our knowledge.

\section{Objective of the Study}

We aimed to evaluate patient satisfaction in patients with custom-fit prostheses of the eye and attempted to analyse the factors that could contribute to dissatisfaction.

Financial or Other, Competing Interest: None.

Submission 09-05-2017, Peer Review 19-07-2017,

Acceptance 25-07-2017, Published 31-07-2017.

Corresponding Author:

Dr. K. S. Rajiv Krishna,

\#31-1-3/1, FF4, Sri Satya Sai Enclave,

Kakarlavari Street, Maruthi Nagar,

Vijayawada-520004.

E-mail: rajivkrishna9@yahoo.in

DOI: $10.14260 /$ jemds/2017/973

\section{MATERIALS AND METHODS}

We conducted a questionnaire-based observational study to evaluate subjective satisfaction in patients with custom-fit prostheses of the eye at our Institute. Ethics Committee approval was obtained.

During 2015, 200 consecutive patients of both sexes and all ages with Custom-fit prostheses who attended the Outpatient Clinic at our Department were included in this study. The clinical examination included socket and fornix examination and evaluation of custom-fit prostheses fitting and symmetry in the ocular movements.

The patients were then asked questions from a specially designed questionnaire and the responses were recorded by the Oculoplasty surgeon. In paediatric patients, responses were elicited from accompanying parents or guardians.

Satisfaction was defined as less than one positive response in the questionnaire and dissatisfaction as one or more positive responses. 


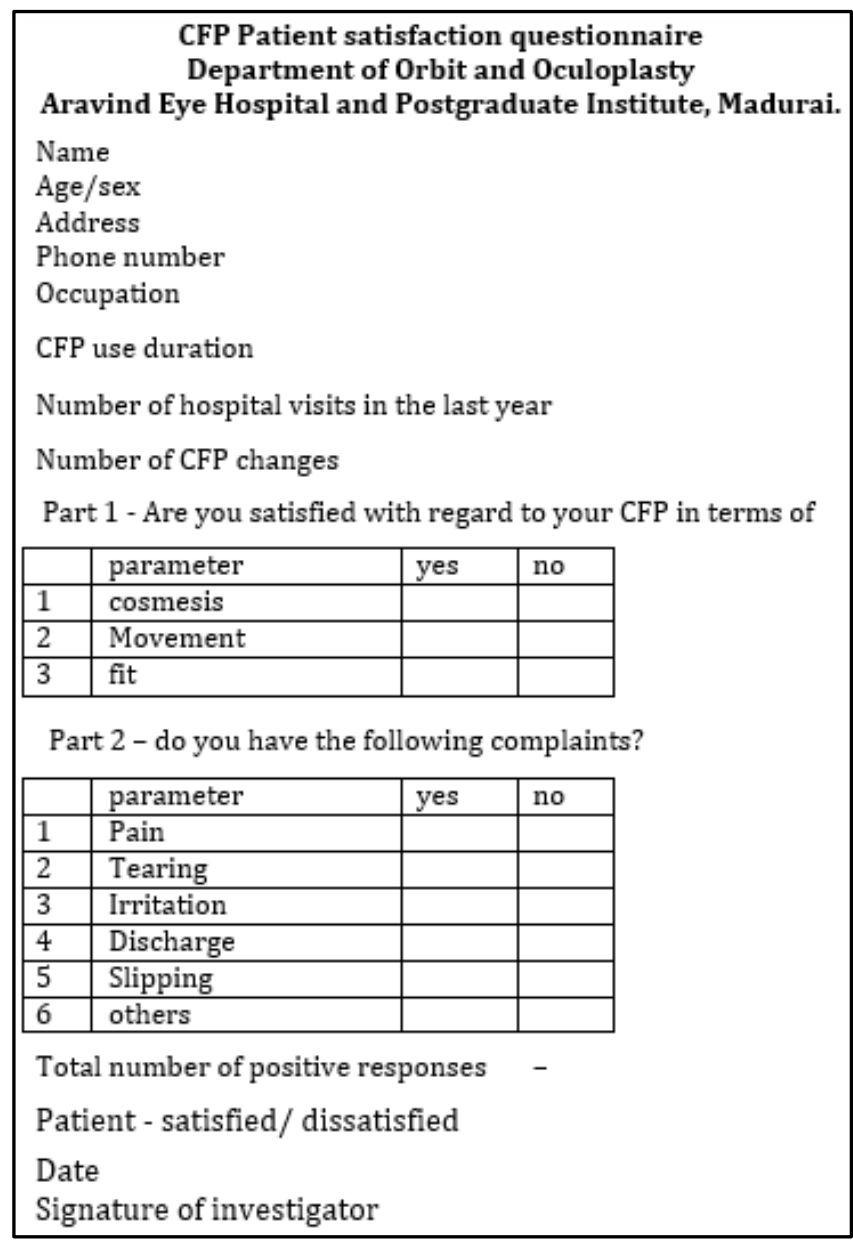

\section{Statistical Analysis}

We took data of 200 consecutive patients using consecutive sampling technique.

We calculated the percentage of satisfied and unsatisfied patients on the whole and in specific subgroups. We compared paediatric and adult age groups, male and female, indication based groups, urban and rural groups and groups based on requirement of additional eye surgeries.

We applied the chi-square test for the different groups and determined the ' $p$ ' value. We assumed ' $p$ ' value less than 0.05 as significant.

We used the StatPac statistical software and www.socscistatistics.com for statistical analysis.

\begin{tabular}{|c|c|c|c|c|c|}
\hline Criteria & Group & $\begin{array}{c}\text { Number } \\
\text { Satisfied Group }\end{array}$ & $\begin{array}{c}\text { Number } \\
\text { Unsatisfied } \\
\text { Group }\end{array}$ & $\begin{array}{c}\% \text { of Satisfied } \\
\text { Patients }\end{array}$ & $\begin{array}{c}\% \text { of Unsatisfied } \\
\text { Patients }\end{array}$ \\
\hline \multirow[t]{2}{*}{ Age } & Paediatric $(<12 \mathrm{y})$ & 19 & 1 & 95 & 5 \\
\hline & Adult & 171 & 9 & 95 & 5 \\
\hline \multirow[t]{2}{*}{ Sex } & Male (130) & 124 & 6 & 95.4 & 4.6 \\
\hline & Female (70) & 67 & 3 & 95.8 & 4.2 \\
\hline \multirow[t]{3}{*}{ Indication } & Trauma (68) & 65 & 3 & 95.4 & 4.6 \\
\hline & Eye Disease (120) & 114 & 6 & 95 & 5 \\
\hline & Mal-develop-ment (12) & 11 & 1 & 90.9 & 9.09 \\
\hline \multirow[t]{2}{*}{ CFP Eye } & Right (114) & 108 & 6 & 94.8 & 5.2 \\
\hline & Left (86) & 82 & 4 & 95.4 & 4.6 \\
\hline \multirow[t]{2}{*}{ Residence } & Urban (108) & 103 & 5 & 95.2 & 4.8 \\
\hline & Rural (92) & 87 & 5 & 94.6 & 5.4 \\
\hline $\begin{array}{l}\text { CFPs placed after } \\
\text { surgical procedures }\end{array}$ & 100 & 95 & 5 & 95 & 5 \\
\hline Additional surgeries required & 30 & 28 & 2 & 93.4 & 6.6 \\
\hline \multicolumn{6}{|c|}{ Table 1. Tabulation of Patients into Groups Based on Criteria Studied } \\
\hline
\end{tabular}

\section{RESULTS}

\begin{tabular}{|c|c|c|c|c|c|}
\hline Group & $\begin{array}{c}\text { No. of } \\
\text { Patients }\end{array}$ & $\begin{array}{c}\text { No } \\
\text { Satisfied }\end{array}$ & $\begin{array}{c}\text { Percentage } \\
\text { Satisfied }\end{array}$ & $\begin{array}{c}\mathbf{C h i}^{2} \\
\text { Value }^{2}\end{array}$ & $\begin{array}{c}\text { P } \\
\text { Value }\end{array}$ \\
\hline Adult & 180 & 171 & 95 & \multirow{2}{*}{0} & \multirow{2}{*}{1} \\
\hline Paediatric & 20 & 19 & 95 & & \\
\cline { 1 - 1 } \\
Table 2. Table showing Paediatric \\
and Adult Group Comparison
\end{tabular}

\begin{tabular}{|c|c|c|c|c|c|}
\hline Group & $\begin{array}{c}\text { No. of } \\
\text { Patients }\end{array}$ & $\begin{array}{c}\text { No } \\
\text { Satisfied }\end{array}$ & $\begin{array}{c}\text { Percentage } \\
\text { Satisfied }\end{array}$ & $\begin{array}{c}\text { Chi }^{2} \\
\text { Value }\end{array}$ & P Value \\
\hline Right & 114 & 108 & 95.2 & 0.0115 & 0.9145 \\
\hline Left & 86 & 82 & 94.6 & & \\
\hline Table 3. Table depicting Right and Left Eye Comparison
\end{tabular}

The data thus obtained was tabulated and analysed.

\begin{tabular}{|c|c|c|c|c|c|}
\hline Group & $\begin{array}{c}\text { No. of } \\
\text { Patients }\end{array}$ & $\begin{array}{c}\text { No } \\
\text { Satisfied }\end{array}$ & $\begin{array}{c}\text { Percentage } \\
\text { Satisfied }\end{array}$ & $\begin{array}{c}\mathbf{C h i}^{2} \\
\text { Value }\end{array}$ & $\begin{array}{c}\text { P } \\
\text { Value }\end{array}$ \\
\hline Male & 130 & 124 & 95.4 & 0.0387 & 0.8441 \\
\hline Female & 70 & 67 & 95.8 & & \\
\hline
\end{tabular}

Table 4. Table showing Sex-Wise Comparison

\begin{tabular}{|l|c|c|c|c|c|}
\hline Group & $\begin{array}{c}\text { No. of } \\
\text { Patients }\end{array}$ & $\begin{array}{c}\text { No } \\
\text { Satisfied }\end{array}$ & $\begin{array}{c}\text { Percentage } \\
\text { Satisfied }\end{array}$ & $\begin{array}{c}\mathbf{C h i}^{2} \\
\text { Value }\end{array}$ & $\begin{array}{c}\text { P } \\
\text { Value }\end{array}$ \\
\hline Urban & 108 & 103 & 94.8 & 0.0678 & 0.7945 \\
\cline { 1 - 3 } & 92 & 87 & 95.4 & & \\
\hline \multicolumn{7}{|c|}{ Table 5. Table comparing Residential Area Based Groups } \\
\hline
\end{tabular}




\begin{tabular}{|c|c|c|c|c|c|}
\hline Group & $\begin{array}{c}\text { No. of } \\
\text { Patients }\end{array}$ & $\begin{array}{c}\text { No } \\
\text { Satisfied }\end{array}$ & $\begin{array}{c}\text { Percentage } \\
\text { Satisfied }\end{array}$ & $\begin{array}{c}\text { Chi }^{2} \\
\text { Value }\end{array}$ & $\begin{array}{c}\text { P } \\
\text { Value }\end{array}$ \\
\hline Trauma & 68 & 65 & 95.4 & & \\
\cline { 1 - 4 } Eye disease & 120 & 114 & 95 & \multirow{2}{*}{0.3302} & 0.8477 \\
$\begin{array}{c}\text { Mal- } \\
\text { development }\end{array}$ & 11 & 1 & 90.9 & & \\
\cline { 1 - 2 } & Table 6. Groups based on Indication Comparison \\
\hline
\end{tabular}

There were 180 adults and 20 paediatric patients in our study and $95 \%$ of patients in both groups were satisfied with the CFP. There was no statistically significant difference in satisfaction when chi-square test with ' $p$ ' value less than 0.05 as significant was applied between groups based on indications for placement of CFP, urban or rural residence and groups according to sex and eye wise.

\section{DISCUSSION}

Clinical challenges in CFP management include impression taking, prosthesis fabrication, identification of the correct orientation into the socket, communication with the patient and satisfaction of patient's expectations. ${ }^{2}$

A properly fitted and accepted custom ocular prosthesis has following characteristics. ${ }^{3}$

- Retains the shape of the defect socket.

- Prevents collapse or loss of the shape of the lids.

- Provides proper muscular action of the lids.

- Prevents accumulation of fluid in the cavity.

- Maintains palpebral opening similar to the natural eye.

- Mimics the coloration and properties of the natural eye.

- Has gaze similar to the natural eye.

In this study among the patients attending the orbit and oculoplasty clinic, majority coming for custom-fit prosthesis were adults $(85.5 \%)$ and paediatric age group accounted for $(14.5 \%)$. Male patients were $(62 \%)$ in study, probably linked to their outdoor activities and injury prone jobs resulting in the loss of the eyeball. Rest (38\%) were females.

The indication for custom-fit prosthesis in our study was found to be trauma in (34\%) cases, which included road traffic accidents and sport injuries. In $(60 \%)$ of the cases, the indication for custom-fit prosthesis was due to various eye diseases like post-operative endophthalmitis, various types of glaucomas, malignancies like retinoblastomas, eye infections leading to either phthisical eye or mandating eye ball removal. (6\%) of the cases in which CFP was indicated is due to congenital anomalies like microphthalmos, anophthalmos and in the cases of the Buphthalmos after the eye ball was removed surgically.

Right eye was involved in (57\%) of cases and left eye was involved in (43\%) of cases. In this study (54\%) patients were from urban areas and (46\%) had rural background. In (50\%) of the patients in the study group, custom-fit prosthesis were placed after surgical procedures like evisceration and enucleation. Additional surgical procedures like Fornix deepening sutures, Dermis-fat grafts ${ }^{4}$ and orbit reconstruction was required in 30 cases accounting for $15 \%$ of the study group.

Patients with CFPs are advised annual followup at the Institute. Of the 200 patients, 11 patients presented to the hospital with complaints in addition to followup visits. CFP change due to various factors were deemed necessary in eight patients.

The surgical procedures for eyeball removal are classified into evisceration, enucleation and exenteration. Until World
War II, the glass eye was the most popular eye prosthesis. The glass eye was, however, difficult to manufacture and hazardous. A definitive technique for fabricating artificial eyes using acrylic resin was developed by the United States Naval Dental and Medical Schools and was published in 1944. Unlike glass eyes which were earlier used, the acrylic resin eyes were solid. The material was light weight, easy to fit and adjust, unbreakable, translucent, easily fabricated, had intrinsic and extrinsic colouring capabilities, and was inert to the socket secretions.5,6,7,8 Flexible material such as silicone is advantageous when the defect extends beyond the orbital area and encounters movable tissue beds.

Advantages of CFP over stock shells- Various size stock shells are readily available in the optical stores. Many patients especially in the small towns and villages try them due to lack of awareness in our country. These stock shells usually do not fit properly and the cosmetic result with them is very poor. Moreover, they cause lot of complications like irritation, socket contracture and granulation tissue formation. Patients tend to lose the stock shells frequently because of small fit. All these factors lead to loss of interest of the patient in cosmetic correction of the empty sockets. Custom-fit prostheses serve as the safest and most effective solution to address the cosmetic aspect of empty sockets.

CFP making process ${ }^{2}$ : Fabrication of CFP is done in the following manner. Socket evaluation is done in detail by the oculoplasty surgeon. In contracted sockets, additional surgical procedures like Fornix deepening sutures or simple surgeries to increase the surface or build in the volume are planned prior to prosthesis fitting to optimise the cosmesis. Later the requirements of the patient are discussed with the ocularist. Ocularist examines the cases and determines the type of prosthesis and the nature of the customisation. If socket is healthy, an impression of the socket is taken using alginate powder. Later wax model with iris button is prepared and patient's comfort and cosmesis are assessed. If found satisfactory, subsequent steps namely stone moulding and acrylic model preparation follow. Finally, the acrylic mould is ground and polished for a glossy finish. Drawing of the Iris pattern and conjunctival vasculature is done in order to match the CFP with the contralateral native eye. Few editorials, texts and case reports available in literature have emphasised the importance of custom-fit prosthesis in the management of the anophthalmic socket.9,10,11

Complications noted in the patients using CFP include foreign body sensation, irritation, discharge, deposits on the CFP and loss of the glossy texture of the CFP. In paediatric age group due to the facial bone growth, socket size varies and therefore mandates periodical review and change of CFP as indicated.

In our study, common factors contributing to dissatisfaction were pain (9) cases, irritation (9) cases, watering (7) cases, ill fit (6) cases, discharge (5) cases. Four patients were not satisfied, because the eye with the prosthesis was not moving in unison with the normal eye. Two patients were unhappy, because the prosthesis which they were using was not giving good cosmesis.

In majority of the cases, pain was due to improper handling and maintenance of the prosthesis resulting in damage to the edges of the prosthesis. Irritation, discharge and watering were due to lack of socket hygiene, especially in the lower socio-economic groups. These patients were either ignorant or non-compliant regarding the standard 
instructions of maintenance, such as periodical cleaning of the prosthesis. Ill fit was found mainly in the paediatric age group, the reason being expansion of the orbital and facial bones during the growing age.

In a few cases, socket granulomas were noted and they were removed surgically and a new custom-fit prosthesis was given. Patients were satisfied with the result. Patient's problems were addressed as per indications and patients and guardians were educated about CFP usage and maintenance.

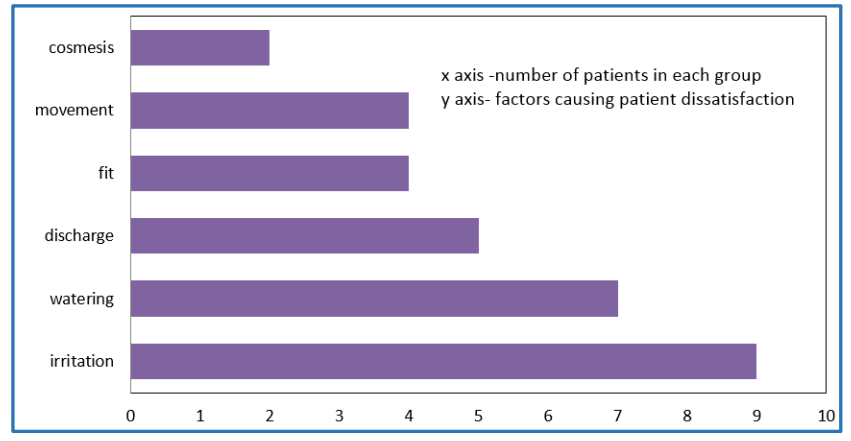

Graph 1. Bar Chart depicting Frequency of Factors causing Dissatisfaction in our Study

\section{CONCLUSION}

Patient satisfaction is the most important aspect in dispensing custom-fit prostheses. This aspect has not been studied thus far adequately. We have attempted to analyse patient's comfort and problems. Most of the patients are satisfied with their prostheses and are enabled for better social and psychological rehabilitation. Most of the problems encountered with the usage of CFP were correctable and minimised by patient education, proper hygiene and counselling. Thus, we conclude that custom-fit prosthesis of the eye is an effective and rational approach in helping patients regain self-confidence and cope with the devastation of loss of vision and or eyeball.

Larger studies are needed to shed light on the problems further and help improve patient care, cosmesis and satisfaction.

Rehabilitation of patients with ocular trauma requires a multidisciplinary approach involving ophthalmologist, psychologist and skilled maxillofacial prosthodontist. ${ }^{12,13}$

Fabrication of a custom-fit ocular prosthesis using socket impression and customised iris button is the gold standard technique in rehabilitating an anophthalmic socket in tertiary eye care centres under the expert supervision of oculoplasty surgeon and trained ocularist. Artificial eyes should be aesthetically pleasing, scratch-resistant and adequately polished. Use of prosthesis without such characteristics can lead to psychological damage as well as infection and inflammation due to the accumulation of microorganisms and other substances on an irregularly shaped prosthesis. ${ }^{6}$

Early referral to CFP capable centres plays a vital role in improving outcomes.

\section{ACKNOWLEDGEMENTS}

1. Consultants, fellows, postgraduate students at the Department of Orbit and Oculoplasty, Aravind Eye Hospital and Postgraduate Institute, Madurai.

2. Nursing, paramedical and office staff at the Department of Orbit and Oculoplasty, Aravind Eye Hospital and Postgraduate Institute, Madurai.

3. All the patients who actively co-operated and took time out to answer the questionnaire.

\section{REFERENCES}

[1] Shaikh SR, Gangurde AP, Shambharkar VI. Changing ocular prostheses in growing children: a 5-year followup clinical report. Journal of Prosthetic Dentistry 2014;111(4):346-8.

[2] Gunaseelaraj R, Karthikeyan S, Kumar MN, et al. Custom-made ocular prosthesis. Journal of Pharmacy \& Bioallied Sciences 2012;4(Suppl 2):S177-9.

[3] Rahn AO, Boucher LJ. Orbital and ocular prosthesis. In: Rahn AO (edr). Maxillofacial prosthetics - principles and concepts. $3^{\text {rd }}$ edn. Philadelphia: W.B. Saunders publishers 1970:151-68.

[4] Aggarwal H, Singh K, Kumar P, et al. A multidisciplinary approach for management of postenucleation socket syndrome with dermis-fat graft and ocular prosthesis: a clinical report. Journal of Prosthodontics 2013;22(8):657-60.

[5] Hatamleh MM, Haylock C, Hollows P, et al. Prosthetic eye rehabilitation and management of completely blind patients. Int J Prosthodont 2012;25(6):631-5.

[6] Goiato MC, Bannwart LC, Haddad MF, et al. Fabrication techniques for ocular prostheses-an overview. Orbit 2014;33(3):229-33.

[7] Sethi T, Kheur M, Haylock C, et al. Fabrication of a custom ocular prosthesis. Middle East African Journal of Ophthalmology 2014;21(3):271-4.

[8] Murphey PJ, Pitton RD, Schlossberg L, et al. The development of acrylic eye prosthesis at the national naval medical center.J Am Dent Assoc 1945;32(19):1227-44.

[9] Agarwal KK, Mall P, Rao J, et al. Fabrication of custom made eye prosthesis for anophthalmic paediatric patients: 2 case reports. J Interdiscip Dentistry 2012;2(2):128-31.

[10] Honavar SG, Kumar R. An eye for an eye. Oman J Ophthalmol 2014;7(3):109-11.

[11] Cerullo L, Mckinstry RE. Ocular prosthesis. In: Mckinstry RE (edr). Fundamentals of facial prosthetics. Arlington: ABI Professional Publishers 1995:99-120.

[12] Kumar P, Aggarwal H, Baslas V, et al. A multidisciplinary approach for rehabilitation following ocular trauma. Burns \& Trauma 2014;2(1):41-4.

[13] Haug SP, Andres CJ. Fabrication of custom ocular prosthesis. In: Taylor TD (edr). Clinical maxillofacial prosthetics. 1 ${ }^{\text {st }}$ edn. Chicago: Quintessence Publishing 2000:265-76. 